\title{
INFLUENCE OF LOW-INTENSITY ANTICOAGULATION AND LOW-DOSE ANTIPLATELET AGENT ON COAGULATION-FIBRINOLYSIS SYSTEM AFTER MECHANICAL PROSTHETIC VALVE REPLACEMENT
}

Yukinori Moriyama, Kazuo Nakamura, Hiroko Kariyazono, Hitoshi Toyohira, and Akira Taira, Kagoshima City, Japan

Mechanical prosthetic heart valve replacement requires lifelong anticoagulant therapy, although the optimal ther-

From the Department of Surgery, Department of Hospital Pharmacy, Kagoshima University, Faculty of Medicine, Kagoshima City, Japan.

Received for publication Nov. 17, 1997; accepted for publication Dec. 8, 1997.

Address for reprints: Y. Moriyama, Second Department of Surgery, Faculty of Medicine, Sakuragaoka 8-35-1, Kagoshima City 890, Japan.

J Thorac Cardiovasc Surg 1998;115:952-4

Copyright (C) 1998 by Mosby, Inc.

$0022-5223 / 98 \$ 5.00+0 \quad \mathbf{1 2 / 5 4 / 8 8 0 0 7}$ apeutic range has not been established. To date several trials have tested the efficacy and safety of combined anticoagulant and antiplatelet therapy for patients with prosthetic valves. ${ }^{1-3}$ In this article we examined the influence of the combination of a less intense program of oral anticoagulation plus low-dose antiplatelets on the coagulation and fibrinolysis systems after prosthetic valve replacement.

Twenty-one patients underwent elective valve replacement with Omnicarbon tilting disc valves (Medical Inc. Inver Grove Heights, Minn.) at our institution. The group comprised 14 men and seven women aged between 27 and 69 years, with a mean age of 51 years. Operative procedures were aortic valve replacement $(n=11)$, mitral valve replacement $(n=9)$, and aortic plus mitral valve replace- 
Table I. Anticoagulation in patients with prosthetic valve replacement $(n=21)$

\begin{tabular}{lccccc}
\hline & \multicolumn{5}{c}{ Duration of warfarin treatment (postoperative months) } \\
\cline { 2 - 5 } & Before & 1 & 6 & 12 & 24 \\
\hline PT-INR & $0.9 \pm 0.1$ & $2.0 \pm 0.6$ & $1.5 \pm 0.4$ & $1.6 \pm 0.5$ & $1.8 \pm 0.5$ \\
WD (mg/day) & 0 & $3.7 \pm 1.9$ & $3.7 \pm 1.7$ & $3.8 \pm 1.6$ & $3.6 \pm 1.7$ \\
WC (ng/ml) & 0 & $843 \pm 261$ & $983 \pm 403$ & $911 \pm 319$ & $893 \pm 384$ \\
PC (\%) & $98 \pm 17$ & $53 \pm 13$ & $62 \pm 17$ & $58 \pm 14$ & $52 \pm 13$ \\
VK1-epo (ng/ml) & 0 & $2.0 \pm 1.3$ & $3.0 \pm 2.4$ & $3.5 \pm 4.1$ & $3.6 \pm 3.6$ \\
\hline
\end{tabular}

$P T$, Prothrombin time; $I N R$, international normalized ratio; $W D$, warfarin dose; $W C$, warfarin concentration; $P C$, protein $C$; $V K_{I}$-epo, vitamin $\mathrm{K}_{1}$-epoxide Values $=$ mean \pm standard deviation.

Table II. Changes in $F_{1+2}, T A T$, and D-dimer $(n=21)$

\begin{tabular}{|c|c|c|c|c|c|}
\hline & \multirow[b]{2}{*}{ Before } & \multicolumn{4}{|c|}{ Duration of warfarin treatment (postoperative months) } \\
\hline & & 1 & 6 & 12 & 24 \\
\hline & & & & $\neg^{*}$ & \\
\hline \multirow{3}{*}{$\begin{array}{l}\mathrm{F}_{1+2}(\mathrm{nmol} / \mathrm{L}) \\
\quad \text { Median (interquartile range) }\end{array}$} & $\mid$ & & $\dagger$ & & $\Rightarrow$ \\
\hline & $8.3(6.3)$ & $5.1(3.9)$ & $5.1(5.1)$ & $4.7(5.0)$ & $2.1(2.4)$ \\
\hline & $\dagger$ & $\dagger$ & & & $\bar{z}$ \\
\hline \multirow{3}{*}{$\begin{array}{l}\text { TAT (ng/ml) } \\
\text { Median (interquartile range) }\end{array}$} & & & & $\dagger$ & \\
\hline & $6.1(6.2)$ & $5.6(3.7)$ & $5.8(8.5)$ & $4.5(4.6)$ & $2.0(1.9)$ \\
\hline & & & $\dagger$ & & \\
\hline \multicolumn{6}{|l|}{ D-dimer $(\mu \mathrm{g} / \mathrm{ml})$} \\
\hline Median (interquartile range) & $5.0(9.6)$ & $6.9(11.5)$ & $11.3(13.5)$ & $12.2(11.5)$ & $1.5(6.4)$ \\
\hline Platelet aggregation (\%) & $\dagger$ & & $\longrightarrow$ & & \\
\hline Median (interquartile range) & $41.0(42.5)$ & $28.0(11.3)$ & $24.0(13.8)$ & $30.0(16.8)$ & $29.0(18.8)$ \\
\hline
\end{tabular}

$F 1+2$, Prothrombin fragment $1+2 ; T A T$, thrombin-antithrombin III complexes. The data are shown as median. Interquartile ranges are in parentheses. ${ }^{*} p<0.05$.

$\dagger p<0.01$.

ment $(n=1)$. Five patients had atrial fibrillation and two had a giant left atrium. However, neither heart failure nor left atrial thrombus was found in any patient before the operation. The dose of warfarin was started at $3 \mathrm{mg} /$ day and adjusted to control prothrombin time/international normalized ratio at around 2.0 in combination with an antiplatelet agent-either aspirin $(81 \mathrm{mg} /$ day, $n=8)$ or ticlopidine (200 mg/day, $n=13$ ). No drugs affecting the blood coagulation system other than these agents were administered. The dynamics of thrombin generation were monitored over a 2-year period using prothrombin fragment $1+2\left(\mathrm{~F}_{1+2}\right)$, thrombin-antithrombin III complex (TAT), D-dimer, and other coagulation-related factors such as warfarin concentration, vitamin $\mathrm{K}_{1}$-epoxide, and protein C. Platelet function was also assessed by maximum aggregation to adenosine diphosphate $(2 \mu \mathrm{mol} / \mathrm{L})$ stimulation. Blood samples were taken before the operation and 1, 6, 12, and 24 months after the operation. Nonparametric data were shown as median with interquartile range, and a multiple comparison test was performed by means of NP Multi.

Table I demonstrated time course of warfarin dose and blood concentrations of related factors. Before the operation, levels of $\mathrm{F}_{1+2}$, TAT, and D-dimer were high, indicating enhanced thrombin production and hyperfibrinolysis. Despite our combined anticoagulant and anti- platelet therapy, the levels of those parameters remained high during the first year after the operation. However, by the end of the second year they decreased significantly and returned to within normal range as compared with those in the first year. Platelet function after the operation was suppressed to a similar degree irrespective of the antiplatelet agent used (Table II). There were no obvious thromboembolic or hemorrhagic complications throughout the follow-up period.

Although many studies have been undertaken to ascertain the appropriate level of anticoagulation in patients with prosthetic valve implants, the optimal range of anticoagulation is still controversial. ${ }^{1,2}$ In general, thromboembolism is reported to occur in up to $2 \%$ of patients per year, and the frequency of major bleeding events ranges between $0.7 \%$ and $6.3 \%$ per patient-year. ${ }^{3}$ For the past 10 years a total of 417 patients have undergone valve replacement surgery with the Omnicarbon tilting disc valve and have been placed on the same anticoagulant therapy as described above at our institution. The total follow-up was 1750 patient-years. The incidences of embolic and hemorrhagic episodes were $0.7 \%$ and $0.6 \%$ per patient-years, respectively. Despite the low rate of embolism in our clinical experience, prosthetic valve replacement induces significant activation of the coagulation and fibrinolysis systems during the subsequent first year. How- 
ever, activation of these systems subsides by the end of the second year, even on a program of low-intensity anticoagulation with low-dose antiplatelet agent.

\section{REFERENCES}

1. Hirsh J, Dalen JE, Deykin D, Poller L, Bussey H. Oral anticoagulants: mechanism of action, clinical effectiveness, and optimal therapeutic range. Chest 1995;108:(suppl):231S-46S.

2. Butchart EG, Lewis PA, Grunkemeier GL, Kulatilake N,
Breckenridge IM. Low risk of thrombosis and serious embolic events despite low-intensity anticoagulation: experience with 1,004 Medtronic Hall valves. Circulation 1988;78(Suppl):I6677.

3. Meschengieser SS, Fondevilla CG, Frontroth J, Santarelli MT, Lazzari MA. Low-intensity oral anticoagulation plus low-dose aspirin versus high-intensity oral anticoagulation alone: a randomized trial in patients with mechanical prosthetic heart valves. J Thorac Cardiovasc Surg 1997;113:910-6. 